\title{
Dietary zinc intake and its determinants among Ethiopian children 6-35 months of age
}

\author{
Girmay Ayana*, Tibebu Moges, Aregash Samuel, Tsehai Asefa, Solomon Eshetu and Aweke Kebede
}

\begin{abstract}
Background: Adequate zinc intake is essential for the growth and neurobehavioral development of young children. Zinc deficiency in children is recognized as risk factor for stunting. In Ethiopia, 38\% of children under five years of age are stunted. This analysis was conducted to measure dietary zinc intake and to identify its determinants among children 6-35 months of age to design appropriate intervention.

Methods: Nationally and regionally representative data available from 6752 children 6-35 months of age from the Ethiopian national food consumption survey were analyzed. A multivariate model was used to identify determinants of dietary zinc intake.

Results: We found low dietary zinc intake among children 6-35 month age. National average dietary zinc intake was 1. $74 \mathrm{mg} /$ day. Socio-economic status, maternal education, and maternal age were positively associated with dietary zinc intake, while the number of children under 5 years-of-age in a household was negatively associated with dietary zinc intake $(p<0.0001)$. Children reportedly sick in the previous 2 weeks were most likely to have low dietary zinc intake $(p<0.0001)$.

Conclusion: The observed low dietary zinc intake in Ethiopian children has a significant association with health status of children, providing evidence for nutrition and health planners to emphasize on promoting consumption of zinc rich foods and preventing morbidity from common infections.
\end{abstract}

Keywords: Stunting, Dietary intake, Zinc, Ethiopia

\section{Background}

Adequate zinc intake is essential for the growth and neurobehavioral development of young children. Low dietary zinc intake is the main cause of zinc deficiency [1]. When zinc rich source foods are not available on a routine diet, zinc deficiency (insufficient zinc to meet the needs of the body) develops over time and persists until changes are made in the diet $[2,3]$. Recent estimates show that $17.3 \%$ of the world's and $23.9 \%$ of Africa's population is at risk of zinc deficiency [4] and 26\% Sub-Saharan Africa people have inadequate access of zinc [5]. Zinc uptake depends on the amount of zinc consumed and the presence of dietary phytate [6]. Even though varied food sources contain zinc, the highest concentrations found in animal-source foods [5]. In developing countries due to economic, cultural and religious

\footnotetext{
* Correspondence: girmayayana@yahoo.com

Ethiopian Public Health Institute, Addis Ababa, Ethiopia
}

constraints, animal source foods consumption is limited and often inaccessible to lower-income households [7].

The first 2 years of life is a crucial period for children growth [4]. Nutrient-rich and diverse diets are essential for children to meet their nutrient needs and support optimal growth [8]. Stunting (height for age $<-2$ SD) is a well-established child health indicator for chronic nutritional problems related to environmental and socio-economic circumstances $[6,9]$. In the absence of direct measure, dietary zinc intake and stunting prevalence are good indicators of a population's risk of zinc deficiency [10]. Because zinc is required for normal linear growth, an elevated prevalence of stunting can be considered as suggestive evidence of an increased risk of zinc deficiency in a population [11].

The high intakes of phytate relative to zinc in the diet of developing countries children, indicate that these children are at great risk for inadequate zinc intake [12].The

(c) The Author(s). 2018 Open Access This article is distributed under the terms of the Creative Commons Attribution 4.0 International License (http://creativecommons.org/licenses/by/4.0/), which permits unrestricted use, distribution, and reproduction in any medium, provided you give appropriate credit to the original author(s) and the source, provide a link to the Creative Commons license, and indicate if changes were made. The Creative Commons Public Domain Dedication waiver (http://creativecommons.org/publicdomain/zero/1.0/) applies to the data made available in this article, unless otherwise stated. 
diets of people living in developing countries are often low in animal products and high in plants or cereal meals high in inhibitors [13]. As a result, the amount of zinc available for absorption from such diets is low, and probably can be the primary cause of zinc deficiency [7].

In Ethiopia animal source food consumption is very low and low quality diet consumption is a common practice. Dietary zinc intake and determining factors among Ethiopia children at national level has not been assessed and reported.Our study aimed at measuring dietary zinc intake and identifying its determinants among children 635 months of age in Ethiopia.

\section{Methods}

Ethiopia has nine regions and two city administrations. The Ethiopian food consumption survey (ENFCS) was a nationally representative population based individual level survey conducted in 2013 to provide evidence about food consumption in Ethiopia. Data was collected on 6752 children from 8267 households. The target population of interest was young children (6-35 months of age) and data was collected on socio-demographic information, anthropometric measurements and dietary intake(using 24-h dietary recall). The $24 \mathrm{~h}$ dietary recall was primarily administered to mother-child pair living in the selected household. For children living without mothers, adult female caregiver was involved. Thus, data were collected from a mother or adult female caregiver and one child in the selected age ranges in each household. For estimation of nutrient intakes, Ethiopian food composition tables were used as a basis for food composition database. To fill missing data gaps in the food composition tables, supplementary datasets and published values were used. Measurements of weight, and length/height were used to assess the nutritional status of children 6-35 months. For analysis purpose, maternal education and maternal age has been categorized. Socioeconomic status of households was also categorized in quartiles. We used bivariate and multivariate analysis model to determine the association of our independent variables with dietary zinc intake,.

In order to ensure informed voluntary participation, the proposal has been submitted for approval to Scientific and Ethical Review Office (SERO) of Ethiopian Public Health Institute and got the final approval. The aim of the survey, as well as the type of measurements to be taken were explained prior to commencing measurements. Verbal consent was obtained from the adult participants, with permission for participation of children. All participants were informed of their option to withdraw from participation at any time.

Regular supervision was undertaken at various levels to ensure the quality of the data. To confirm the quality of data, supervisors had conducted truncated spot-checks in $10 \%$ of interviewed households.
In this paper we report findings on determinants of dietary zinc intake among children 6-35 months of age as well as the association between dietary zinc intake and height for age. We used data available from children 6-35 months of age for analysis of dietary zinc intake. A general linear model was used to identify determinants of dietary zinc intake and to determine association between height for age and dietary zinc intake in children

Table 1 Socioeconomic and demographic characteristics of households with children 6-35 month age, Ethiopia

\begin{tabular}{|c|c|c|}
\hline Socioeconomic and demographic characteristics & $\mathrm{n}$ & Percent \\
\hline Household head level of education & 4954 & \\
\hline No education & & 34.4 \\
\hline Can read and write & & 8.6 \\
\hline Primary, 1st cycle & & 11.8 \\
\hline Primary, 2nd cycle & & 20.9 \\
\hline High school & & 17.3 \\
\hline Tertiary level & & 6.9 \\
\hline Head of household employment & 4904 & \\
\hline Self employed & & 77.1 \\
\hline Employed & & 8.8 \\
\hline Public service worker & & 4.7 \\
\hline Unpaid family worker & & 1.3 \\
\hline Other & & 8.1 \\
\hline Women's relationship to child & 7640 & \\
\hline Biological Mother & & 95.0 \\
\hline Caregiver & & 5.0 \\
\hline Mother's/women caregiver's employment & 7636 & \\
\hline Self employed & & 43.8 \\
\hline Employed & & 2.8 \\
\hline Public service worker & & 1.4 \\
\hline Unpaid family worker & & 43.1 \\
\hline Other & & 9.0 \\
\hline Mother's/women's caregiver's level of education & 7835 & \\
\hline No education & & 58.7 \\
\hline Can read and write & & 2.8 \\
\hline Primary, 1st cycle & & 10.6 \\
\hline Primary, 2nd cycle & & 12.2 \\
\hline High School & & 11.4 \\
\hline Other & & 4.3 \\
\hline Wealth index & 7906 & \\
\hline Poorest & & 23.1 \\
\hline Second & & 20.4 \\
\hline Middle & & 19.2 \\
\hline Fourth & & 18.0 \\
\hline Richest & & 19.3 \\
\hline
\end{tabular}


Table 2 Prevalence of under nutrition in children 6-35 month age in Ethiopia

\begin{tabular}{|c|c|c|c|c|c|c|c|c|c|}
\hline \multirow[t]{2}{*}{ Region } & \multicolumn{3}{|c|}{ Stunting Prevalence (\%) } & \multicolumn{3}{|c|}{ Wasting Prevalence (\%) } & \multicolumn{3}{|c|}{ Underweight Prevalence (\%) } \\
\hline & $\mathrm{N}$ & $<-3 S D$ & $<-2 S D$ & $\mathrm{~N}$ & $<-3 S D$ & $<-2 S D$ & $\mathrm{n}$ & $<-3 S D$ & $<-2 S D$ \\
\hline Tigray & 640 & 18.1 & 47.7 & 639 & 1.7 & 8.9 & 638 & 6.8 & 28.4 \\
\hline Afar & 497 & 17.7 & 36.1 & 492 & 6.6 & 26.0 & 494 & 16 & 38.6 \\
\hline Amhara & 825 & 21 & 44.9 & 822 & 1.4 & 8.1 & 823 & 7.6 & 27.9 \\
\hline Oromiya & 921 & 15.3 & 34.9 & 918 & 1.6 & 8.9 & 920 & 8 & 22.4 \\
\hline Somali & 615 & 11.2 & 27.4 & 612 & 3.2 & 13.1 & 614 & 7.2 & 22.5 \\
\hline B/Gumuz & 501 & 18.8 & 38.4 & 500 & 3.9 & 15.1 & 501 & 11.2 & 27.6 \\
\hline SNNP & 893 & 18.6 & 40.7 & 891 & 1.2 & 6.3 & 893 & 7 & 21.9 \\
\hline Gambella & 415 & 10.1 & 24.4 & 415 & 3.1 & 13.9 & 415 & 6.3 & 21.5 \\
\hline Harari & 383 & 12.9 & 31.0 & 382 & 1.2 & 8.2 & 383 & 4.9 & 20.8 \\
\hline A/ Ababa & 572 & 6.6 & 19.4 & 570 & 0.7 & 3.2 & 572 & 2 & 7.6 \\
\hline Dire Dawa & 440 & 10.8 & 27.7 & 440 & 2.6 & 10.6 & 440 & 5 & 19.9 \\
\hline Total & 6702 & 17.2 & 38.7 & 6681 & 1.6 & 8.4 & 6693 & 7.5 & 23.8 \\
\hline
\end{tabular}

aged 6-35 months in Ethiopia. Zinc intake was not normally distributed therefore, during analysis we transformed the data to the $\log 10$ form. This was back transformed in the result writing.

\section{Results}

\section{Socio demographic characteristics of household with} children 6-35 month months age

Majority of mothers/care givers had low formal education level (58.7\%). Women were more likely to be involved in unpaid family work than head of households.
The respondents were fairly evenly distributed across all wealth indexes (Table 1).

\section{Children nutritional status}

High stunting prevalence was found in the agrarian regions and relatively low stunting prevalence was found in the pastoralist community. The prevalence of stunting was above the national level of $38.7 \%$ in the South $\mathrm{Na}$ tions Nationalities and People (40.7\%), Amhara (44.9\%) and Tigray (47.7\%) regions. Lowest stunting prevalence was found in Gambela (24.4\%) and Addis Ababa (19.4\%) regions (Table 2).

Table 3 Average dietary zinc intake ( $\mathrm{mg} / 24 \mathrm{~h}$ ) among children 6-35 months of age, Ethiopia

\begin{tabular}{|c|c|c|c|c|c|}
\hline Variables & & N & Average $\mathrm{Zn}$ intake (mg/24 h) & $\mathrm{SE}(95 \% \mathrm{Cl})$ & $p$-value \\
\hline \multirow[t]{2}{*}{ Residence } & Urban & 1757 & 1.51 & $1.00[1.5,1.51]$ & 0.126 \\
\hline & Rural & 4831 & 1.65 & $1.00[1.64,1.65]$ & \\
\hline \multirow[t]{5}{*}{ SES } & Poorest & 1315 & 1.48 & $1.00[1.48,1.48]$ & $<0.0001$ \\
\hline & Second & 1342 & 1.61 & $1.00[1.61,1.61]$ & \\
\hline & Middle & 1319 & 1.48 & $1.00[1.48,1.49]$ & \\
\hline & Fourth & 1343 & 1.64 & $1.00[1.63,1.64]$ & \\
\hline & Richest & 1269 & 1.68 & $1.00[1.68,1.69]$ & \\
\hline \multirow[t]{6}{*}{ Mother's education } & Illiterate & 4001 & 1.00 & $1.00[1.00,1.00]$ & $<0.0001$ \\
\hline & Can read and write & 168 & 1.00 & $1.00[1.00,1.00]$ & \\
\hline & Primary school, (G:1-4) & 698 & 1.56 & $1.00[1.55,1.56]$ & \\
\hline & Primary school (G:5-8) & 901 & 1.47 & $1.00[1.46,1.47]$ & \\
\hline & High school & 643 & 1.61 & $1.00[1.61,1.61]$ & \\
\hline & other & 177 & 1.58 & $1.00[1.57,1.58]$ & \\
\hline \multirow[t]{2}{*}{ Child Breast feeding } & No & 2167 & 1.71 & $1.00[1.71,1.71]$ & $<0.0001$ \\
\hline & Yes & 4421 & 1.00 & $1.00[1.00,1.00]$ & \\
\hline \multirow[t]{2}{*}{ Child sex } & Male & 3525 & 1.88 & $1.00[1.88,1.89]$ & 0.141 \\
\hline & Female & 3063 & 1.32 & $1.00[1.32,1.32]$ & \\
\hline
\end{tabular}




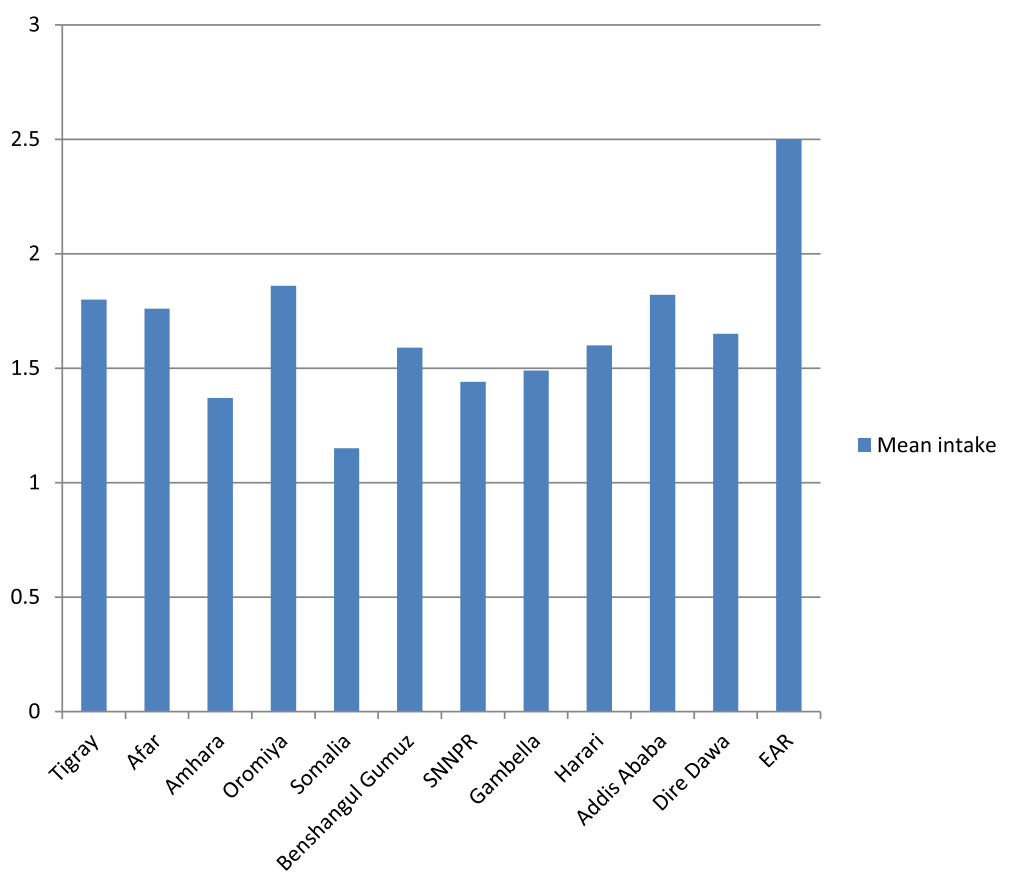

Fig. 1 Mean dietary zinc intake of children 6-35 months of age by regions, Ethiopia

\section{Children average dietary zinc intake ( $\mathrm{mg} / 24 \mathrm{~h}$ ) in Ethiopia} From the bivariate analysis, We found no difference between urban and rural children in mean dietary zinc intake(1.51 versus $1.65, P=0.126)$. Dietary zinc intake varied with socioeconomic status of the households. Maternal education has association with zinc intake. Non breast feeding children had a higher dietary zinc intake than breastfeeding(Table 3).

\section{Mean dietary zinc intake among children aged 6-35 months $(N=6752)$}

A total of 6752 data were analyzed to measure dietary zinc intake among children 6-35 months of age in all regions/city administrations. We found low dietary zinc consumption among children over the country. Nationally, mean dietary zinc intake of children 6-35 months of age was $1.74 \mathrm{mg} /$ day. Children's mean dietary zinc intake was highest in Oromia region and Addis Ababa city. The lowest mean dietary zinc intake found in Somali and Amhara region (Fig. 1).

\section{Determinants of dietary zinc intake in children 6-35 months age}

Maternal age, female relationship to a child and child sickness in the previous two weeks had a significant association with the children dietary zinc intake $(p$ value $<0.0001)$. The intake of dietary zinc has no association with household socioeconomic status and child sex. Place of residence/region has also a significant association with dietary intake (Table 4).

\section{Discussion}

We found low mean dietary zinc intake in Ethiopian children. Children from illiterate mothers had lower dietary zinc intake than those from educated mothers and current breastfeeding children had lower dietary zinc intake than non breastfed children. Children's place of residence has no significant difference on their dietary zinc intake. The main determinants of dietary intake in Ethiopian children were child health status, child age, maternal education status and child relationship to a mother.

Children nutritional status in Ethiopia is generally poor, and under-nourishment is one of the major health problems. The prevalence of stunting and underweight is

Table 4 Determinants of mean dietary zinc intake among children 6-35 month in Ethiopia

\begin{tabular}{lll}
\hline Independent variable & Regression coefficient & $p$-value \\
\hline Child age & -0.02 & $<0.0001$ \\
Number of children $<5$ yrs & -0.11 & 0.71 \\
Female relationship to child & 0.14 & $<0.0001$ \\
Child sex & 0.01 & 0.016 \\
Child sickness in previous 2 weeks & 0.13 & $<0.0001$ \\
Place of residence (urban/rural) & 0.04 & 0.004 \\
SES quintile & 0.06 & 0.19 \\
Mother's age & 0.02 & $<0.0001$ \\
Mothers education status & 0.41 & 0.004 \\
Head of household education status & 0.35 & 0.84 \\
Region & 0.16 & $<0.0001$ \\
\hline
\end{tabular}


considerably high in Ethiopia [14]. Children from developing countries has limited access to animal source food [15] and consume less amount of zinc which resulted in children's restricted growth [16]. In Ethiopia cereals consumption on average accounts for more than $60 \%$ of the total households [17] and low dietary diversity and inappropriate child feeding practices [18] had contribution to the unacceptable stunting prevalence. Increased consumption of animal-source foods and phytate reduction are the preferred approaches to enhance content and bioavailability of $\mathrm{Zn}$ in the diets of rural households in developing countries [16]. Consumption of animal source foods and increasing dietary diversification could reduce stunting in children [19].Children from lower-income settings with inadequate intake and poor absorption from cereal-based complementary foods had a higher risk of zinc deficiency [20]. A study conducted in southern Ethiopia had confirmed that zinc intakes in pregnant women was very low and it was below reported level in many developing countries [21]. Our study also revealed inadequate dietary zinc intake in Ethiopian children. Similar to our finding a study conducted in Uganda has also shown that zinc intake does not meet the requirement in children [22].

Our study indicated that dietary intake of zinc is associated with the household income and educational status of caregivers/mothers. Similar to our finding in Ugandan children, consumption of meat and fish as well as their zinc intake was found high among communities of higher socioeconomic status.

One of the limitation in our study was, it didn't consider calculating phytate zinc molar ratio for the dietary intake. The study did not estimate the contribution of breast milk to zinc intake among children still being breastfed and due to cost implication of dietary data collection, a single 24-h dietary recall was completed for each children. Therefore, intra-individual variation could not quantified.

\section{Conclusion}

Dietary zinc intake among 6-35 months age children is very low in Ethiopia. Considering the high prevalence of stunting and roles of adequate zinc intake in supporting normal growth, nutrition and health planners need to emphasize on promoting zinc rich foods consumption and preventing childhood morbidity from common infections.

\footnotetext{
Abbreviations

Cl: Confidence Interval; EAR: Estimated Average Requirement; ENFCS: Ethiopian National Food Consumption Survey; Mg: Milligram; SD: Standard Deviation; SE: Standard Error; SNNPR: South Nations Nationalities and People Region
}

\section{Acknowledgements}

The authors gratefully acknowledge the contribution of Ethiopian Public Health Institute in managing overall the Ethiopian food consumption survey. We also thank to Ethiopian Federal Ministry of health, regional health office for their collaboration and facilitation of data collection and all households for providing the necessary information. The authors also would like to acknowledge Mihretab Melese (PhD) for his contribution in reviewing and editing the manuscript.

\section{Availability of data and materials}

The data that supports the findings of this study are available from Ethiopian Public Health Institute, Food Science and Nutrition Research Directorate.

\section{Authors' contributions}

GA conceived the idea, designed the objectives, analyzed data and wrote the manuscript. TM, AS,TA, SE and AK involved in the design of national food consumption survey, coordination of field work, analyses of data and critically commented and approved the manuscript.

\section{Ethics approval and consent to participate}

Ethical approval was provided by Ethics Review Committee of Ethiopian Public Health Institute. All participants involved in the study were asked to their consent and they provided verbal consent.

Consent for publication

Not applicable

\section{Competing interests}

The authors declare that they have no competing interests.

\section{Publisher's Note}

Springer Nature remains neutral with regard to jurisdictional claims in published maps and institutional affiliations.

Received: 9 January 2018 Accepted: 21 June 2018

Published online: 09 August 2018

\section{References}

1. Thompson B, Amoroso L. Combating micronutrient deficiencies food-based approaches. In: Rome; Wallingford, Oxfordshire. Cambridge: Food and agriculture Organization of the United Nations; CABl; 2011.

2. Caulfield LE, Black RE. "Zinc deficiency," Comp Quantif Heal risks Glob Reg Burd Dis Attrib to Sel major risk factors Geneva World Heal Organ. 2004; 257-79.

3. Salgueiro MJ, Zubillaga MB, Lysionek AE, Caro RA, Weill R, Boccio JR. The role of zinc in the growth and development of children. Nutrition. 2002; 18(6):510-9.

4. Black RE, Victora CG, Walker SP, Bhutta ZA, Christian P, de Onis M, Ezzati M, Grantham-McGregor S, Katz J, Martorell R, Uauy R. Maternal and child undernutrition and overweight in low-income and middle-income countries. Lancet. 2013;382(9890):427-51.

5. Wessells KR, Brown KH. Estimating the global prevalence of zinc deficiency: results based on zinc availability in National Food Supplies and the prevalence of stunting. PLoS One. 2012;7(11):e50568.

6. Engle-Stone R, Ndjebayi AO, Nankap M, Killilea DW, Brown KH. "Stunting prevalence, plasma zinc concentrations, and dietary zinc intakes in a nationally representative sample suggest a high risk of zinc deficiency among women and young children in Cameroon," J Nutr.2014;p. jn-113.

7. Gibson RS. Zinc: the missing link in combating micronutrient malnutrition in developing countries. Proc Nutr Soc. 2006;65(01):51-60.

8. Nguyen PH, Avula R, Ruel MT, Saha KK, Ali D, Tran LM, Frongillo EA, Menon $P$, Rawat R. Maternal and child dietary diversity are associated in Bangladesh, Vietnam, and Ethiopia. J Nutr. Jul. 2013;143(7):1176-83.

9. Lewit EM, Kerrebrock N. Population-based growth stunting. Futur Child. 1997:149-56.

10. Davidsson L, Fontaine O, Hotz C. Conclusions of the joint WHO/UNICEF/ IAEA/IZiNCG interagency meeting on zinc status indicators. Food Nutr Bull. 2007;28(3):2007.

11. Gibson RS. Zinc nutrition in developing countries. Nutr Res Rev. 1994;7(01): 151-73.

12. Roohani N. "Human zinc nutrition in arid regions with zinc deficiency in soils and crops," Diss, Eidgenössische Technische Hochschule ETH Zürich, Nr. 2012;20393:2012

13. Brown $\mathrm{KH}$. "Information gaps for scaling-up programs to improve zinc nutrition". Clin Nutr. 2007;72:1516-22. 
14. Central Statistical Agency [Ethiopia] and ICF International. Ethiopia Demographic and Health Survey. Addis Ababa: Ethiopia and Calverton, Maryland, USA; 2012.

15. Brown $\mathrm{KH}$. "Information gaps for scaling-up programs to improve zinc Nutrition". 2005.

16. Gibson RS. "The rank prize lecture Zinc: the missing link in combating micronutrient malnutrition in developing countries," no. 2005, pp. 51-60, 2006.

17. Berhane G, Paulos Z, Tafere K, Tamiru S. "Foodgrain consumption and calorie intake patterns in Ethiopia". 2011;23.

18. Umeta M, West CE, Verhoef H, Haidar J, Hautvast JG. "Community and International Nutrition Factors Associated with Stunting in Infants Aged 5-11 Months in the Dodota-Sire District, Rural Ethiopia 1". 2003;no. August 2002, pp. 1064-1069.

19. Darapheak C, Takano T, Kizuki M, Nakamura K, Seino K. Consumption of animal source foods and dietary diversity reduce stunting in children in Cambodia. Int Arch Med. 2013;6(1):29.

20. Bhatnagar S, Natchu UC. Zinc in child health and disease. Indian J Pediatr. 2004;71(11):991-5.

21. Abebe Y, Bogale A, Hambidge KM, Stoecker BJ, Arbide I, Teshome A, Krebs $N F$, Westcott JE, Bailey KB, Gibson RS. "Inadequate intakes of dietary zinc among pregnant women from subsistence households in Sidama, Southern Ethiopia,". Public Health Nutr. 2007;11(4):379-86.

22. Tidemann-andersen I, Acham H, Maage A, Malde MK. "Iron and zinc content of selected foods in the diet of schoolchildren in Kumi district, east of Uganda: a cross-sectional study". 2011;1-12.

Ready to submit your research? Choose BMC and benefit from:

- fast, convenient online submission

- thorough peer review by experienced researchers in your field

- rapid publication on acceptance

- support for research data, including large and complex data types

- gold Open Access which fosters wider collaboration and increased citations

- maximum visibility for your research: over $100 \mathrm{M}$ website views per year

At BMC, research is always in progress.

Learn more biomedcentral.com/submissions 